\title{
Influence of the selected active substances of fungicides on the growth of Trichoderma viride
}

\author{
Wpływ wybranych substancji czynnych fungicydów \\ na wzrost Trichoderma viride
}

Ilona Świerczyńska, Agnieszka Perek, Katarzyna Pieczul

\section{Summary}

The fungi of Trichoderma genus as antagonists of plant pathogenic fungi can reduce development of plant diseases. They also positively affect agriculture value of the soil and support plant resistance. Therefore Trichoderma spp. are used as bioproducts in a biological plant protection. However, the use of fungicides due to their efficiencies or a combination of both methods are the common practices in the crop protection. The aim of the study was to estimate the effect of 13 active substances of fungicides on the growth of $T$. viride under the laboratory conditions. Among 13 active ingredients carbendazim showed the strongest impact on the $T$. viride development; at each dose inhibited completely the colony growth. The least toxic to $T$. viride were azoxystrobin, kresoximmethyl, cyproconazole and tetraconazole.

Key words: Trichoderma viride; active substance of fungicides; in vitro growth inhibition

\section{Streszczenie}

Grzyby rodzaju Trichoderma wykazują skuteczne działanie antagonistyczne przeciwko grzybom patogenicznym ograniczając rozwój chorób roślin. Wpływają również korzystnie na wartość rolniczą gleby oraz wspomagają odporność roślin. Z tego względu Trichoderma spp. wykorzystywane są w biologicznej ochronie roślin jako biopreparaty. Powszechną praktyką w ochronie roślin jest jednak stosowanie fungicydów z uwagi na skuteczniejsze działanie lub łączenie obydwu metod. W przeprowadzonym doświadczeniu badano wpływ 13 substancji czynnych, będących składnikami fungicydów, na wzrost kolonii $T$. viride w warunkach laboratoryjnych. Najsilniejszym oddziaływaniem wykazał się karbendazym, który w każdej dawce całkowicie zahamował wzrost kolonii grzyba T. viride. Najmniej toksyczne dla T. viride okazały się: azoksystrobina, krezoksym metylu, cyprokonazol i tetrakonazol.

Słowa kluczowe: Trichoderma viride; substancja czynna fungicydu; hamowanie wzrostu in vitro

\author{
Instytut Ochrony Roślin - Państwowy Instytut Badawczy \\ Zakład Mikologii \\ Władysława Węgorka 20, 60-318 Poznań \\ I.Swierczynska@iorpib.poznan.pl
}




\section{Wstęp / Introduction}

Gatunki rodzaju Trichoderma są saprofitycznymi grzybami występującymi powszechnie w środowisku naturalnym. Ze względu na właściwości antagonistyczne grzyby tego rodzaju wykorzystywane są w biologicznej ochronie roślin, np. w postaci biopreparatów (Wojtkowiak-Gębarowska 2006). T. viride wykazuje silne działanie mykopasożytnicze w stosunku do wielu patogenów roślin w tym m.in. Fusarium spp., Pythium spp., Rhizoctonia spp. (Wojtkowiak-Gębarowska i Pietr 2006). Jednocześnie pozytywnie oddziałuje na kondycję roślin stymulując ich wzrost oraz poprawiając wartość rolniczą gleby. Wymienione korzyści powodują, że $T$. viride w niektórych warunkach może skutecznie zastapić chemiczne środki ochrony roślin lub umożliwić zredukowanie ich dawek (Khalko i wsp. 2006; Ashraf i Zuhaib 2013). Aby zintegrowana ochrona przy użyciu fungicydu i antagonisty była efektywna należy ocenić, które substancje czynne i w jakich stężeniach mogą hamować rozwój patogena bez negatywnego wpływu na antagonistę (Kumar i Gupta 1999; Dubey i Patel 2001; Khalko i wsp. 2006; Madhavi i wsp. 2011).

Celem badań była ocena wpływu substancji czynnych wchodzących w skład powszechnie stosowanych fungicydów na wzrost kolonii $T$. viride.

\section{Materiały i metody / Materials and methods}

Do badań wykorzystano trzynaście czystych substancji czynnych (Sigma) należących do grup: strobiluryn (azoksystrobina, krezoksym metylu, piraklostrobina), anilinopirymidyn (cyprodinil), triazoli (cyprokonazol, epoksykonazol, flusilazol, tebukonazol, tetrakonazol), imidazoli (prochloraz), morfolin (fenpropimorf) oraz benzimidazoli (karbendazym i tiofanat metylowy). Badane związki zostały rozpuszczone w metanolu w stężeniu $5 \mathrm{mg} / \mathrm{ml}$. Każdą z substancji czynnych dodano do sterylnej pożywki PDA (Potato Dextrose Agar; Difco) w dawkach: 1, 3 i 10 ppm, a następnie rozlano na płytki Petriego $(90 \mathrm{~mm})$. Na tak przygotowane podłoża wyszczepiono centralnie krążki pożywki PDA o powierzchni $0,5 \mathrm{~cm}^{2}$, przerośnięte grzybnią $T$. viride. Wykorzystany w badaniu izolat $T$. viride został wcześniej wyizolowany z gleby i oznaczony makroskopowo oraz mikroskopowo do gatunku. Kontrolę stanowiły kultury $T$. viride wyszczepione $\mathrm{w}$ ten sam sposób na pożywkę PDA bez dodatku substancji czynnych. Doświadczenie przeprowadzono w pięciu powtórzeniach. Średnice kolonii $T$. viride mierzono po pięciu dniach licząc od momentu inokulacji. Analizie statystycznej poddano różnice wzrostu grzybów rosnących na pożywce PDA oraz na pożywce $\mathrm{z}$ dodatkiem substancji czynnych. Zastosowano analizę wariancji dwuczynnikowej przy użyciu testu Duncana na poziomie istotności $\alpha=0,05$.

\section{Wyniki i dyskusja / Results and discussion}

Zastosowane w doświadczeniu substancje czynne środków ochrony roślin dodane do pożywki PDA wykazały zróżnicowany wpływ na wzrost liniowy $T$. viride (tab. 1).
Wszystkie substancje czynne najsilniej hamowały rozwój grzyba w dawce 10 ppm. Większość substancji czynnych wykazała słabsze, hamujące oddziaływanie w dawce 3 ppm oraz najsłabsze w stężeniu 1 ppm. Tylko azoksystrobina i cyprodinil dodane do pożywki w stężeniach 1 i 3 ppm oddziaływały podobnie na wzrost $T$. viride, a jedyną substancją, której działanie było podobne we wszystkich badanych dawkach był karbendazym. Środek wykazał najsilniejsze, hamujące oddziaływanie na rozwój grzyba ograniczające całkowicie jego wzrost. Podobne dane otrzymali Dubey i Patel (2001), Singh i Varma (2005), Khalko i wsp. (2006), Khan i Shahzad (2007) Amalraj i wsp. (2010) oraz Devi i Singh (2012). W badaniach wymienionych autorów karbendazym wykazał najsilniejsze działanie toksyczne na $T$. viride. Malathi i wsp. (2002) stwierdzili, że izolaty $T$. viride nie rozwijały się na pożywkach z dodatkiem karbendazymu w dawce powyżej 1 ppm. Khan i Shahzad (2007) stwierdzili silne działanie hamujące karbendazymu na wzrost kolonii $T$. viride już w dawce 1 ppm i coraz silniejsze w przypadku wzrostu koncentracji tej substancji czynnej. Uzyskane wyniki wskazują na brak możliwości łączenia karbendazymu wraz z biologiczną ochroną roślin opartą na biopreparatach zawierających $T$. viride.

Część z badanych substancji czynnych dodanych do pożywki w stężeniu $1 \mathrm{ppm}$ nie hamowała wzrostu $T$. viride. Średnica kolonii rosnących na pożywkach z zawartością 1 ppm azoksystrobiny, cyprodinilu, cyprokonazolu, krezoksymu metylu, tetrakonazolu oraz tiofanatu metylowego nie różniła się od wielkości kolonii rosnących w kombinacji kontrolnej i wynosiła $90 \mathrm{~mm}$ po 5 dniach inkubacji (tab. 1). W podobnym doświadczeniu Malathi i wsp. (2002) wykazali, że tiofanat metylowy, zastosowany w dawce $1 \mathrm{ppm}$, nie hamował wzrostu $T$. viride. Jednakże podwyższenie zawartości tej substancji czynnej do $5 \mathrm{ppm}$ powodowało całkowite zahamowanie wzrostu $T$. viride. Pozostałe substancje czynne w dawce 1 ppm wykazały wyraźne oddziaływanie hamujące na liniowy wzrost kolonii grzyba. Prochloraz ograniczył wzrost kultury T. viride o $84 \%$. Nieco słabsze oddziaływanie wykazał epoksykonazol (63,6\% hamowania wzrostu), fenpropimorf $(52,4 \%)$, tebukonazol $(55,3 \%)$ i piraklostrobina $(42,9 \%)$. Stosunkowo słabe oddziaływanie na rozwój antagonisty wykazywał flusilazol (18,9\% hamowania wzrostu) (tab. 1).

$\mathrm{W}$ dawce $3 \mathrm{ppm}$ jedynie azoksystrobina i cyprodinil nie wykazały działania hamującego na wzrost kolonii $T$. viride. Cyprokonazol, krezoksym metylu oraz tetrakonazol, które w dawce 1 ppm nie ograniczyły wzrostu kolonii, w stężeniu 3 ppm tylko nieznacznie zahamowały rozwój grzybni T. viride (odpowiednio o 2, 8,7 i 2\%). Niewielkie oddziałływanie hamujące na $T$. viride wykazywały flusilazol $(34,7 \%)$ i tiofanat metylowy $(19,6 \%)$ (tab. 1). Wymienione substancje czynne mogą być więc wykorzystane w trakcie stosowania biologicznej ochrony roślin, nie powodując zahamowania rozwoju antagonisty. Podobne wyniki otrzymali Dubey i Patel (2001) stosując m.in. tiofanat metylowy. W badaniach tych autorów działanie hamujące tej substancji czynnej na wzrost grzyba $T$. viride było niewielkie, ale w miarę zwiększenia koncentracji w pożywce coraz silniejsze. Khan i Shahzad (2007) wykazali brak hamowania wzrostu kultur $T$. viride po 5 dniach inkubacji 
Tabela 1. Średnica [mm] oraz procent hamowania wzrostu u 5-dniowych kolonii $T$. viride

Table 1. The diameter [mm] and percentage of growth inhibition of 5-day-old colonies of $T$. viride

\begin{tabular}{|c|c|c|c|c|c|}
\hline \multirow{2}{*}{$\begin{array}{l}\text { Substancje czynne } \\
\text { Active substances }\end{array}$} & \multirow{2}{*}{$\begin{array}{l}\text { Grupa fungicydu } \\
\text { Group of fungicide }\end{array}$} & \multicolumn{3}{|c|}{$\begin{array}{l}\text { Zawartość substancji czynnej w pożywce [ppm] } \\
\text { Content of active substance in the medium [ppm] }\end{array}$} & \multirow{2}{*}{$\begin{array}{c}\text { Średnia } \\
\text { dla substancji czynnej } \\
\text { Mean for active substance }\end{array}$} \\
\hline & & 1 & 3 & 10 & \\
\hline Azoxystrobin & strobilurin & $90,0(0 \%) \mathrm{m}$ & $90,0(0 \%) \mathrm{m}$ & $76,4(15,1 \%) \mathrm{jk}$ & $85,5(5 \%) \mathrm{j}$ \\
\hline Cyprodinil & anilinopyrimidine & $90,0(0 \%) \mathrm{m}$ & $90,0(0 \%) \mathrm{m}$ & $56,0(37,8 \%) \mathrm{h}$ & $78,7(12,6 \%) \mathrm{i}$ \\
\hline Cyproconazole & triazole & $90,0(0 \%) \mathrm{m}$ & $88,2(2 \%) \mathrm{m}$ & $71,8(20,2 \%) \mathrm{i}$ & $83,3(7,4 \%) \mathrm{j}$ \\
\hline Epoxiconazole & triazole & $32,8(63,6 \%)$ e & $16,2(82 \%) \mathrm{c}$ & $9,4(89,6 \%) b$ & $19,5(78,3 \%) \mathrm{c}$ \\
\hline Fenpropimorph & morpholine & $42,8(52,4 \%) \mathrm{f}$ & $28,4(68,4 \%) \mathrm{d}$ & $17,0(81,1 \%) \mathrm{c}$ & $29,4(67,3 \%) \mathrm{e}$ \\
\hline Flusilazole & triazole & $73,0(18,9 \%) \mathrm{ij}$ & $58,8(34,7 \%) \mathrm{h}$ & $41,4(54 \%) \mathrm{f}$ & $57,7(35,9 \%) \mathrm{g}$ \\
\hline Carbendazim & benzimidazole & $0,0(100 \%) \mathrm{a}$ & $0,0(100 \%) \mathrm{a}$ & $0,0(100 \%) \mathrm{a}$ & $0,0(100 \%) \mathrm{a}$ \\
\hline Kresoxim-methyl & strobilurin & $90,0(0 \%) \mathrm{m}$ & $82,2(8,7 \%) 1$ & $77,4(14 \%) \mathrm{k}$ & $83,2(7,6 \%) \mathrm{j}$ \\
\hline Pyraclostrobin & strobilurin & $51,4(42,9 \%) \mathrm{g}$ & $34,6(61,6 \%) \mathrm{e}$ & $27,0(70 \%) \mathrm{d}$ & $37,7(58,1 \%) \mathrm{f}$ \\
\hline Prochloraz & amidazile & $14,4(84 \%) \mathrm{c}$ & $8,8(90,2 \%)$ ab & $7,8(91,3 \%)$ ab & $10,3(88,6 \%) b$ \\
\hline Tebuconazole & triazole & $40,2(55,3 \%) \mathrm{f}$ & $17,8(80,2 \%) \mathrm{c}$ & $10,0(88,9 \%) b$ & $22,7(74,8 \%) \mathrm{d}$ \\
\hline Tetraconazole & triazole & $90,0(0 \%) \mathrm{m}$ & $88,2(2 \%) \mathrm{m}$ & $74,8(16,9 \%) \mathrm{i}-\mathrm{k}$ & $84,3(6,3 \%) \mathrm{j}$ \\
\hline Tiophanate-methyl & benzimidazole & $90,0(0 \%) \mathrm{m}$ & $72,4(19,6 \%) \mathrm{ij}$ & $35,4(60,7 \%) \mathrm{e}$ & $65,9(26,8 \%) \mathrm{h}$ \\
\hline Kontrola - Control & & $90,0 \mathrm{~m}$ & $90,0 \mathrm{~m}$ & $90,0 \mathrm{~m}$ & $90,0 \mathrm{k}$ \\
\hline \multicolumn{2}{|c|}{$\begin{array}{l}\text { Średnia dla substancji czynnych } \\
\text { w poszczególnych dawkach } \\
\text { Mean for active substances for each dose }\end{array}$} & $63,5(29,4 \%) \mathrm{c}$ & $55,0(38,9 \%) b$ & $42,8(52,4 \%)$ a & \\
\hline
\end{tabular}

Średnie oznaczone tą samą literą nie różnią się między sobą na poziomie istotności $\alpha=0,05$

Means followed by the same letter do not differ significantly at $\alpha=0.05$

w obecności tiofanatu metylowego w dawce 1 i $10 \mathrm{ppm}$. $\mathrm{W}$ przeprowadzonych badaniach najsilniej w dawce $3 \mathrm{ppm}$ oddziaływał karbendazym (100\% hamowania wzrostu) i prochloraz $(90,2 \%)$ prawie zupełnie ograniczając wzrost kolonii, następnie epoksykonazol (82\%), tebukonazol $(80,2 \%)$, fenpropimorf $(68,4 \%)$ i piraklostrobina $(61,6 \%)$ (tab. 1).

Substancje czynne dodane do pożywki w dawce 10 ppm wywarły najbardziej zróżnicowany wpływ na wzrost kolonii grzybów (od 14 do 100\%) (tab. 1). Wśród najaktywniejszych substancji czynnych znalazły się: karbendazym, prochloraz, epoksykonazol i tebukonazol, które skutecznie zahamowały wzrost kolonii. Silne działanie hamujące tebukonazolu na $T$. viride stwierdził Bagwan (2010). W badaniach autora środek ten dodany do pożywki w zalecanej dawce całkowicie hamował wzrost 3-dniowych kultur $T$. viride. Fenpropimorf, piraklostrobina, tiofanat metylowy i flusilazol znacznie ograniczyły wzrost kolonii grzyba - odpowiednio o 81,1, 70, 60,7 i 54\%. Najsłabsze działanie hamujące wykazały cyprodinil $(37,8 \%)$, cyprokonazol $(20,2 \%)$, tetrakonazol $(16,9 \%)$, azoksystrobina $(15,1 \%)$ oraz krezoksym metylu (14\%). Podobnie w badaniach Archana i wsp. (2012) azoksystrobina dodana do pożywki $w$ dawce 10 ppm nie hamowała wzrostu kultur $T$. viride po 5 dniach inkubacji. Także w badaniach Ranganathswamy i wsp. (2013) spośród zastosowanych substancji czynnych azoksystrobina znalazła się wśród substancji najsłabiej działających na $T$. viride. Sarkar i wsp. (2008) badając wpływ azoksystrobiny i tebukonazolu stwierdzili skuteczniejsze działanie hamu- jące rozwój $T$. harzianum w przypadku tebukonazolu i słabe w odniesieniu do azoksystrobiny.

Uzyskane wyniki wskazują, że możliwe jest dobranie fungicydów do łącznego stosowania $\mathrm{z}$ biopreparatami opartymi na $T$. viride. Mało toksyczne dla $T$. viride są: azoksystrobina, krezoksym metylu, cyprokonazol, tetrakonazol i cyprodinil. Do substancji czynnych, których zdecydowanie należy unikać stosując biopreparaty zawierające T. viride należą: karbendazym, prochloraz, epoksylonazol i tebukonzol. Ciekawą obserwacją jest różne oddziaływanie na wzrost kolonii $T$. viride substancji czynnych należących do tej samej grupy chemicznej fungicydów, nie różniących się mechanizmem działania grzybobójczego. Azoksystrobina i krezoksym metylu (strobiluryny) nie wykazywały silnego wpływu na hamowanie wzrostu kolonii T. viride (średnia hamowania wzrostu 5 i 7,6\%), inaczej niż kolejna substancja z tej grupy - piraklostrobina, która średnio ograniczyła wzrost badanych izolatów o $58,1 \%$. Podobne wyniki uzyskano dla fungicydów z grupy triazoli. Do substancji bezpiecznych dla $T$. viride możemy zaliczyć cyprokonazol i tetrakonazol (średnie hamowania wzrostu 7,4 i 6,3\%), a zdecydowanie hamujących wzrost epoksykonazol i tebukonazol (średnie hamowania wzrostu 78,3 i 74,8\%) (tab. 1).

\section{Wnioski / Conclusions}

1. Najmniej toksyczne dla T. viride okazały się: azoksystrobina, krezoksym metylu, cyprokonazol, tetrakonazol 
i cyprodinil. Stosowanie fungicydów zawierających wymienione substancje czynne wydaje się bezpieczne dla prawidłowego funkcjonowania $T$. viride.

2. Karbendazym całkowicie, a prochloraz, epoksylonazol i tebukonzol bardzo silnie hamowały wzrost $T$. viride we wszystkich zastosowanych stężeniach, co wyklucza łączne stosowanie fungicydów $\mathrm{z}$ wymienionymi sub- stancjami czynnymi z biopreparatami zawierającymi T. viride.

3. Wszystkie substancje czynne najsilniej hamowały wzrost $T$. viride w dawce $10 \mathrm{ppm}$, co wskazuje na korzyści ze stosowania możliwie najniższych zalecanych dawek fungicydów wraz $\mathrm{z}$ ochroną biologiczną preparatami zawierającymi $T$. viride.

\section{Literatura / References}

Amalraj L.D.E., Kumar P.G., Desai S., Ahmed M.H.S.K. 2010. In vitro characterization of Trichoderma viride for abiotic stress tolerance and field evaluation against root rot disease in Vigna mungo L. J. Biofertil. Biopestici. 2 (3): 1-5.

Archana S., Hubballi M., Ranjitham T.P., Prabakar K., Raguchander T. 2012. Compatibility of azoxystrobin 23 SC with biocontrol agents and insecticides. Madras Agric. J. 99 (4-6): 374-377.

Ashraf S., Zuhaib M. 2013. Fungal biodiversity: a potential tool in plant disease management. p. 69-90. In: „Management of Microbial Resources in the Environment" (A. Malik, E. Grohmann, M. Alves, eds). Springer, Berlin, 532 pp.

Bagwan N.B. 2010. Evaluation of Trichoderma compatibility with fungicides, pesticides, organic cakes and botanicals for integrated management of soil borne disease of soybean [Glycine max (L.) Merril]. Int. J. Plant Prot. 3 (2): 206-209.

Devi T.N., Singh M.S. 2012. Evaluation of suitable fungicide for integration with Trichoderma isolates for the control of tomato wilt. J. Mycopathol. Res. 50 (2): 223-228.

Dubey S.C., Patel B. 2001. Determination of tolerance in Thanatephorus cucumeris, Trichoderma viride, Gliocladium virens and Rhizobium sp. to fungicides. Indian Phytopathol. 54 (1): 98-101.

Khalko S., Jash S., Bose S., Roy M., Pan S. 2006. Evaluation of tolerance in Macrophomina phaseolina, Trichoderma harzianum, Trichoderma viride and Gliocladium virens to fungicides. J. Mycopathol. Res. 44 (1): 109-111.

Khan M.O., Shahzad S. 2007. Screening of Trichoderma species for tolerance to fungicides. Pak. J. Bot. 39 (3): $945-951$.

Kumar A., Gupta J.P. 1999. Variations in enzyme activity of tebuconazole tolerant biotypes of Trichoderma viride. Indian Phytopathol. 52 (3): 263-266.

Madhavi G.B., Bhattiprolu S.L., Reddy V.B. 2011. Compatibility of biocontrol agent Trichoderma viride with various pesticides. J. Hortlic. Sci. 6 (1): 71-73.

Malathi P., Viswanathan R., Padmanaban P., Mohanraj D., Sunder A.R. 2002. Compatibility of biocontrol agents with fungicides against red rot disease of sugarcane. Sugar Tech. 4 (3-4): 131-136.

Ranganathswamy M., Patibanda A.K., Rao G.N. 2013. Evaluation of toxicity of agrochemicals on Trichoderma isolates in vitro. J. Mycopathol. Res. 51 (2): 289-293.

Sarkar S., Narayanan P., Divakaran A., Balamurugan A., Premkumar R. 2008. The in vitro effect of certain fungicides, insecticides, and biopesticides on mycelial growth in the biocontrol fungus Trichoderma harzianum. Turk. J. Biol. 34 (2010): 399-403.

Singh G., Varma R.K. 2005. Compatibility of fungicides and neem products against Fusarium solani f. sp. glycines causing root rot of soybean and Trichoderma spp. J. Mycopathol. Res. 43 (2): 211-214.

Wojtkowiak-Gębarowska E. 2006. Mechanizmy zwalczania fitopatogenów glebowych przez grzyby z rodzaju Trichoderma. Post. Mikrobiol. 45 (4): 261-273.

Wojtkowiak-Gębarowska E., Pietr S.J. 2006. Colonization of roots and growth stimulation of cucumber by iprodione-resistant isolates of Trichoderma spp. applied alone and combined with fungicides. Phytopathol. Pol. 41: 51-64. 